\title{
STRATEGI PEMASARAN TEH HITAM MERK “ALAM DEMPO" PADA CV. KARYA SEJAHTERA PAGAR ALAM
}

\section{Marketing Strategy of Black Tea Brand "Alam Dempo" of CV. Karya Sejahtera Pagar Alam}

\author{
Tiffany Siti Khadijah, Irnad, dan Satria Putra Utama \\ Jurusan Sosial Ekonomi Pertanian Fakultas Pertanian Universitas Bengkulu
}

\begin{abstract}
This study aims to determine the main criterion used in marketing strategies and the strategies marketing appropriate and effective in marketing black tea brands "Alam Dempo" on CV. Karya Sejahtera. The primary data was obtained from interviews and secondary data obtained from the data from of the company, regulations, and others data from the related agencies. The data was analyzed by using the AHP (Analytical Hierarchy Process) with Application Expert Choice 11. The results of research show that the criteria becomes main priority election marketing strategies black tea was is competitor with weight 0.385. This occurred due to large number of business contractors packaging black tea other products. To alternate top priority marketing strategies was chosen by method AHP is promotion strategy with weight 0,360 .
\end{abstract}

Keywords: blacktea, marketing strategy, AHP (Analitycal Hierarchy Process)

\section{PENDAHULUAN}

Pembangunan pertanian merupakan salah satu tulang punggung pembangunan nasional dan implementasinya harus sinergis dengan pembangunan sektor lainnya. Pelaku pembangunan pertanian meliputi departemen teknis terkait, pemerintah daerah, petani, pihak swasta, masyakarat dan pengambil kebijakan (stakeholder) lainnya (Wahyu, 2011).

Sektor pertanian mempunyai peranan yang sangat besar dalam pertumbuhan ekonomi negara terutama negara yang bercorak agraris seperti Indonesia. Pembangunan ekonomi menitik beratkan pada bidang pertanian dan industri yang berbasis pertanian atau biasa disebut agroindustri. Dalam sistem agribisnis, agroindustri adalah salah satu subsistem yang bersama-sama subsistem lain membentuk agribisnis (Valentina, 2009).

Teh merupakan sumber non-migas yang mantap sebagai sumber devisa bagi Negara maupun sebagai penyedia lapangan kerja dan pendapatan petani. Industri teh yang terdiri dari 90 persen teh hitam dan 10 persen teh hijau menyumbang Produk Domestik Bruto (PDB) sekitar Rp 1,2 trilyun (0,3 persen dari total PDB non migas) dan menyumbang devisa bersih sekitar 110 juta dollar per tahun. Tanaman teh sebagai tanaman perdagangan, semakin 
berkembang pesat, jenis tanaman teh juga berkembang menjadi beraneka ragam. Teh banyak digemari masyarakat di Indonesia maupun diluar negeri, namun konsumsi teh di Indonesia masih rendah, yaitu 190 g/ kapita/ tahun. Oleh sebab itu, usaha perkebunan teh baik dari perkebunan rakyat, swasta maupun perkebunan Negara sebagai produsen berorientasi ekspor, industri dan konsumsi dalam negeri (Nimpatupulu 1992).

Teh hitam merupakan jenis teh yang paling umum di Asia Selatan (India, SriLangka, Bangladesh) dan sebagian besar negara-negara di Afrika seperti: Kenya, Burundi, Rwanda, Malawi dan Zimbabwe. Teh hitam sama dengan teh hijau yang berbeda hanyalah proses pengolahannya, dimana dihasilkan melalui sistem pengolahan yang melakukan proses fermentasi didalam proses pengolahannya.

Dalam pengembangannya produk teh hitam di pasaran saat ini banyak sekali jenis-jenisnya mulai dari teh celup, teh kotak, teh yang langsung diminum tanpa melakukan proses penyaringan. Sedangkan CV. Karya Sejahtera saat ini masih memproduksi jenis teh hitam tubruk dan teh celup. Teh hitam merk alam dempo dipasarkan di daerah Kota Pagar Alam. CV. Karya Sejahtera belum menerapkan strategi pemasaran yang maksimal.

Persaingan didunia bisnis semakin meningkat dengan ketat, barang, dan jasa yang ada dipasaran bisa memiliki keseragaman antara produk yang satu dengan yang lainnya. Hal ini dapat terjadi karena suatu produk satu yang sukses akan diikuti oleh para pesaing dengan menghasilkan produk sejenis dengan produk tersebut. Sehingga perlu adanya peningkatan didalam strategi pemasaran (Zumroh, 2014). Dengan demikian CV. Karya Sejahtera perlu merumuskan strategi pemasaran yang efektif agar produk teh hitam ini kedepannya akan mampu bersaing terhadap industri pengemasan teh hitam lainnya. Prioritas strategi pemasaran yang efektif sebagai upaya agar teh hitam merk alam dempo dapat terus berkembang

\section{METODE PENELITIAN}

Penelitian ini dilakukan di CV. Karya Sejahtera pada bulan Apri - Mei 2016. Responden ditentukan dengan purposive yang memiliki pengetahuan menunjang berkenaan dengan kebutuhan penelitian sehingga tidak mempunyai jumlah minimal yang dibutuhkan.

Data yang digunakan dalam penelitian ini adalah data primer dan sekunder. Data primer diperoleh dari wawancara dengan responden dengan menggunakan kuisioner. Sedangkan data sekunder diperoleh dari data yang dimiliki perusahan berupa laporan, peraturan, dan lainnya serta data yang berasal dari instansi yang terkait.

Analisis data dalam menentukan prioritas prioritas strategi pemasaran akan dianalisis dengan metode analisis AHP (Analytical Hierarchy Process). Dengan metode AHP diawali dengan pengumpulan data dan menyusun 
struktur Hierarki. Dalam penelitian ini, metode analisis data menggunakan software Expert Choice 11 dan Microsoft Excel.

Adapun langkah dan prosedur dalam penggunaan metode AHP adalah sebagai berikut :

1. Menyusun hirarki yang digunakan untuk menguraikan permasalahan dalam mengidentifikasi faktor dalam strategi pemasaran industri kopi bubuk aroma yang diprioritaskan dan kemudian menyusun matriks banding berpasangannya.

2. Menentukan nilai tentang kepentingan relatif dari dua elemen melalui kuisioner berdasarkan input dari para pakar/ahli (expert) menggunakan nilai skala banding berpasangan seperti pada tabel di bawah ini :

\section{Tabel 1. Penilaian kriteria dan alternatif}

\begin{tabular}{cl}
\hline Nilai & \multicolumn{1}{c}{ Keterangan } \\
\hline $\mathbf{1}$ & Kriteria/alternatif A sama penting dengan kriteria/alternatif \\
& B \\
$\mathbf{3}$ & A sedikit lebih penting dari B \\
$\mathbf{5}$ & A jelas lebih penting dari B \\
$\mathbf{7}$ & A sangat jelas lebih penting dari B \\
$\mathbf{2} \mathbf{4}, \mathbf{6 , 8}$ & Mutlak lebih penting dari B \\
\hline
\end{tabular}
Sumber: Saaty (1983) dalam Nuryasri (2014)

Nilai perbandingan A dengan B adalah 1 (satu) dibagi dengan nilai perbandingan B dengan A. Pendapat para ahli (expert) yang konsisten kemudian akan digabungkan dengan menggunakan rata-rata geometrik (Marimin, 2004) :

$$
\overline{\mathrm{X}}_{\mathrm{G}}=\sqrt[n]{n_{1} \mathrm{x} n_{2} \mathrm{x} \ldots \ldots \times \mathrm{x} n_{n}}
$$

Dengan:

$\overline{\mathrm{X}}_{\mathrm{G}}=$ Rata-rata geometrik

$\mathrm{n} \quad=$ Jumlah responden

$\mathrm{n}_{1} \quad=$ Penilaian responden ke-1

$\mathrm{n}_{2}=$ Penilaian responden ke- 2

$\mathrm{n}_{\mathrm{n}} \quad=$ Penilaian oleh responden ke-n

3. Melakukan sintesis hasil dari penilaian yang telah dilakukan yaitu mengukur bobot prioritas setiap elemen tersebut dengan dasar persepsi seorang ahli (expert).

4. Melakukan pengecekan konsistensi yang berguna untuk mengidentifikasi kemungkinan-kemungkinan kesalahan dalam penilaian sebagaimana adanya terjadinya inkonsistensi dalam penilaian. Jika tidak memenuhi syarat dengan nilai Rasio Inkonsistensi $(\mathrm{CR}) \leq 0,1$ maka penilaian harus diulang kembali. 


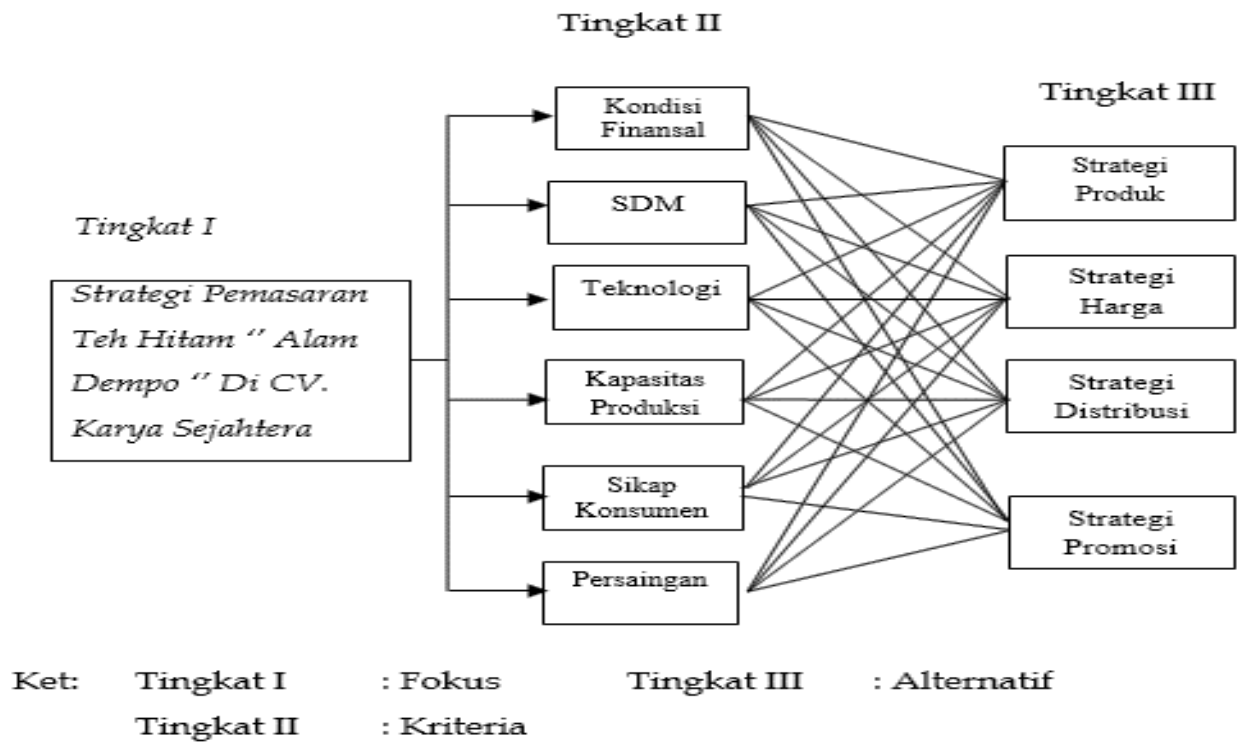

\section{HASIL DAN PEMBAHASAN}

\section{Analisis Penilaian Derajat Kepentingan Kriteria Pemilihan Strategi Pemasaran}

Analisis nilai bobot pada tingkat 2 bertujuan untuk mengetahui urutan prioritas dari kriteria-kriteria pemilihan strategi pemasaran produk Teh Hitam Alam Dempo. Hasil analisis nilai bobot kriteria disajikan pada tabel berikut:

Tabel 2 . Nilai bobot kriteria Pemilihan Prioritas Strategi Pemasaran

\begin{tabular}{lcc}
\hline \multicolumn{1}{c}{ Kriteria } & Bobot & Prioritas \\
\hline Kondisi Finansial & 0.139 & 3 \\
Sumber Daya Manusia & 0.066 & 6 \\
Teknologi & 0.097 & 5 \\
Kapasitas Produksi & 0.200 & 2 \\
Sikap Konsumen & 0.113 & 4 \\
Persaingan & 0.385 & 1 \\
\hline Rasio Inkonsistensi Keseluruhan (\%) & 0.01 atau 1\% &
\end{tabular}

Sumber: Data Primer Diolah (2016)

Dari hasil analisis yang di dapat menggunakan metode AHP dan di aplikasikan dengan Expert Choice 11, bahwa nilai bobot yang paling tinggi adalah kriteria persaingan dengan bobot 0,385. Prioritas kedua yaitu kriteria kapasitas produksi dengan bobot 0,200. Prioritas ketiga yaitu kriteria Kondisi Finansial dengan bobot 0,139. Prioritas keempat yaitu kriteria Sikap Konsumen dengan bobot 0,113 . Prioritas kelima yaitu kriteria Teknologi dengan bobot 0,97 dan yang menjadi prioritas terakhir yaitu kriteria sumber daya manusia dengan bobot 0,066 . Inconsistensi yang di dapat 0,01 atau $1 \%$. 
Menurut Zakiyah (2008) dalam Fatma (2014) rasio konsistensi hirarki harus $10 \%$ atau kurang. Jika tidak, mutu informasi harus diperbaiki, antara lain dengan memperbaiki cara menggunakan pertanyaan ketika melakukan pengisian ulang kuisoner atau lebih baik dalam mengarahkan responden yang mengisi kuisoner. Jika hasil menunjukkan kurang dari 10\% maka hasil tersebut telah konsisten.

Dengan nilai Dari beberapa kriteria pada penelitian ini yang dijadikan prioritas dalam kriteria strategi pemasaran teh hitam alam dempo pada $\mathrm{CV}$. Karya Sejahtera adalah kriteria persaingan. Persaingan menjadi prioritas pertama dikarenakan persaingan di kota pagar alam pada produk teh hitam cukup banyak, dan hal tersebut akan sangat mempengaruhi pendapatan dari perusahaan. Persaingan disini dapat dilihat dari kualitas, kemasan, ukuran, harga, dan pelayanan.

Kapasitas produksi menjadi prioritas kedua karena Karena kapasitas produksi adalah jumlah maksimum output yang dapat diproduksi atau dihasilkan dalam satuan waktu tertentu. Kapasitas produksi yang didapatkan dari kegiatan produksi pengemasan teh hitam ini adalah 300 kotak per minggunya. Kapasitas produksi ini nantinya akan mempengaruhi pendapatan yang didapat oleh CV. Karya Sejahtera.

Kondisi finansial perusahaan menjadi prioritas ketiga. Menurut Ramadhany dalam Wijaya (2014) Kondisi keuangan perusahaan merupakan suatu tampilan atau keadaan secara utuh atas keuangan perusahaan selama periode waktu tertentu. Kondisi keuangan merupakan gambaran kinerja sebuah perusahaan. Kondisi keuangan perusahaan menggambarkan tingkat kesehatan perusahaan sesungguhnya. Kondisi finansial perusahaan CV. Karya Sejahtera sangat mempengaruhi pendapatan dari perusahaan. Kondisi ini merupakan suatu keadaan dimana perusahaan dapat tetap beroperasi dalam jangka waktu kedepan, kegagalan dalam menghasilkan laba dapat mengancam perusahaan.

Pada prioritas keempat yang berpengaruh dalam memilih alternatif strategi pemasaran adalah sikap konsumen. Sikap adalah suatu kecederungan yang dipelajari untuk bereaksi terhadap kehadiran produk dalam masalahmasalah yang baik ataupun kurang baik. Sikap biasanya memberikan penilaian (menerima atau menolak) terhadap objek atau produk yang dihadapi.

Prioritas kelima adalah teknologi. Teknologi pada saat ini sangat berkembang di berbagai wilayah. Teknologi mesin saat ini sangat banyak digunakan oleh pengusaha-pengusaha karena Penerapan teknologi pada bidang bisnis dapat mengefisiensikan waktu, biaya, dan tenaga. Contohnya dengan menggunakan mesin teh celup mempermudah proses pengemasan teh celup tanpa harus menggunakan tenaga yang cukup banyak.

Sumber daya manusia menjadi prioritas terakhir, Sumber daya manusia adalah individu yang bekerja sebagai penggerak perusahaan dan berfungsi sebagai riset yang harus dilatih dan dikembangkan kemampuannya, karena tanpa adanya manusia suatu kegiatan tidak mungkin dapat berjalan. 
ISSN: 1412-8837

Ditengah-tengah pesatnya kecanggihan teknologi ternyata peran SDM dalam menentukan keberhasilan perusahaan tidak bisa diabaikan, SDM merupakan sumber keunggulan daya saing.

\section{Analisis Penilaian Derajat Kepentingan Pemilihan Alternatif Strategi Pemasaran}

Analisis penilaian bobot alternatif masing-masing kriteria bertujuan mengetahui urutan prioritas dari alternatif strategi pemasaran CV. Karya Sejahtera adapun hasil nilai bobot alternatif masing-masing kriteria adalah sebagai berikut :

\section{Tabel 3. Nilai Bobot Alternatif Berdasarkan Kriteria}

\begin{tabular}{|c|c|c|c|c|}
\hline $\begin{array}{c}\text { Kriteria prioritas } \\
\text { strategi pemasaran }\end{array}$ & Alternatif strategi & Bobot & Prioritas & $\begin{array}{c}\text { Rasio } \\
\text { Inkonsistensi }\end{array}$ \\
\hline \multirow{4}{*}{ Kondisi Finansial } & Strategi Produk & 0.250 & 2 & \multirow{4}{*}{$\begin{array}{c}0.008 \\
(0.8 \%)\end{array}$} \\
\hline & Strategi Harga & 0.156 & 3 & \\
\hline & Strategi Distribusi & 0.126 & 4 & \\
\hline & Strategi Promosi & 0.468 & 1 & \\
\hline \multirow{4}{*}{ Sumber Daya Manusia } & Strategi Produk & 0.165 & 4 & \multirow{4}{*}{$\begin{array}{c}0.002 \\
(0.2 \%)\end{array}$} \\
\hline & Strategi Harga & 0.189 & 3 & \\
\hline & Strategi Distribusi & 0.203 & 2 & \\
\hline & Strategi Promosi & 0.443 & 1 & \\
\hline \multirow[t]{4}{*}{ Teknologi } & Strategi Produk & 0.345 & 1 & \multirow{4}{*}{$\begin{array}{c}0.006 \\
(0,6 \%)\end{array}$} \\
\hline & Strategi Harga & 0.312 & 2 & \\
\hline & Strategi Distribusi & 0.152 & 4 & \\
\hline & Strategi Promosi & 0.191 & 3 & \\
\hline \multirow{4}{*}{ Kapasitas Produksi } & Strategi Produk & 0.415 & 1 & \multirow{4}{*}{$\begin{array}{c}0.003 \\
(0,3 \%)\end{array}$} \\
\hline & Strategi Harga & 0.262 & 2 & \\
\hline & StrategiDistribusi & 0.199 & 3 & \\
\hline & Strategi Promosi & 0.124 & 4 & \\
\hline \multirow{4}{*}{ Sikap Konsumen } & Strategi Produk & 0,251 & 2 & \multirow{4}{*}{$\begin{array}{c}0.002 \\
(0,2 \%)\end{array}$} \\
\hline & Strategi Harga & 0,233 & 3 & \\
\hline & StrategiDistribusi & 0,083 & 4 & \\
\hline & Strategi Promosi & 0.433 & 1 & \\
\hline \multirow{4}{*}{ Persaingan } & Strategi Produk & 0.204 & 2 & \multirow{4}{*}{$\begin{array}{c}0.006 \\
(0.6 \%)\end{array}$} \\
\hline & Strategi Harga & 0.170 & 4 & \\
\hline & Strategi Distribusi & 0.173 & 3 & \\
\hline & Strategi Promosi & 0.453 & 1 & \\
\hline
\end{tabular}

Sumber: Data Primer Diolah (2016)

Berdasarkan hasil pengolahan dari kriteria kondisi finansial perusahaan, Strategi promosi menjadi prioritas utama dalam pemilihan strategi pemasaran teh hitam alam dempo dengan bobot nilai sebesar 0,468. Strategi promosi dianggap perlu dilakukan agar dapat mempertahankan kondisi keuangan perusahaan. Semakin banyak produk yang dibeli oleh konsumen tentunya ini akan menambah pendapatan dari CV. Karya Sejahtera. Karena itu persaingan menjadi prioritas yang paling penting dalam kriteria ini. Dengan adanya 
strategi promosi yang menarik membuat masyrarakat lebih tertarik dan menyukai produk teh hitam alam dempo.

Hasil pengolahan dari kriteria Sumber Daya Manusia, Strategi promosi menjadi prioritas pertama dengan bobot nilai sebesar 0,443. Promosi merupakan salah satu variabel marketing mix yang sangat penting yang dilakukan untuk membuka pangsa pasar yang baru atau memperluas jaringan pemasaran. Strategi promosi dianggap perlu dalam strategi pemasaran teh hitam alam dempo. Promosi dapat juga dilakukan oleh tenaga SDM namun hal ini belum diterapkan oleh CV .Karya Sejahtera, agar produk teh hitam ini akan lebih dikenal lagi di pasaran.

Untuk kriteria teknologi strategi produk menjadi prioritas pertama Bobotnya adalah 0,343. Dengan adanya teknologi pada CV. Karya Sejahtera harus mempertahankan kualitas, Harga dan kemasan penting bagi usaha untuk mendukung daya saing produk.

Untuk kriteria kapasitas produksi yang menjadi prioritas pertamanya adalah strategi produk dengan bobot sebesar 0,415. kapasitas poduksi dapat diartikan sebagai jumlah maksimum output yang dapat diproduksi atau dihasilkan dalam satuan waktu tertentu, kapasitas produksi merupakan salah satu hal yang perlu diperhatikan sehubungan dengan upaya meningkatkan laba peusahaan. Kapasitas produksi dapat mengambarkan kemampuan perusahaan dalam memenuhi permintaan pasar, semakin tinggi kapasitas produksi yang dapat diusahakan maka semakin banyak produk yang mampu dihasilkan setiap hari, bulan, bahkan setiap tahunnya. Strategi kapasitas produk harus mampu menciptakan harga di pasaran dapat bersaing di pasaran.

Menurut Kotler dan Amstrong (2008), tahap-tahap yang biasa dilalui konsumen dalam proses mereka untuk melakukan pembelian meliputi kesadaran, keyakinan dan pembelian. Berdasarkan kriteria sikap konsumen yang menjadi prioritas pertama adalah sub kriteria promosi dengan bobot yaitu 0,433. Dimana Strategi promosi merupakan faktor penentu keberhasilan suatu program pemasaran yang dilakukan oleh perusahan. Betapapun berkualitasnya suatu produk, bila konsumen belum pernah mendengarnya dan tidak yakin bahwa produk tersebut akan berguna bagi mereka, maka konsumen tidak akan tertarik dan tidak akan membelinya.

Kriteria persaingan strategi pertama adalah strategi promosi dengan bobot sebesar 0,453 . Promosi adalah salah satu faktor yang diperlukan bagi keberhasilan dan strategi pemasaran yang diterapkan suatu perusahaan terutama pada saat ini ketika era informasi berkembang pesat, maka promosi merupakan salah satu senjata ampuh perusahaan dalam mengembangkan dan mempertahankan usaha. Suatu produk tidak akan dibeli bahkan dikenal apabila konsumen tidak mengetahui kegunaannya, keunggulan, dimana produk dapat diperoleh dan berapa harganya. Untuk itulah CV. Karya Sejahtera memerlukan strategi promosi dalam menarik minat konsumen dan tetap mempertahankan konsumen. Apalagi dengan banyaknya pesaing teh hitam alam dempo CV. Karya Sejahtera. 
Tabel 4. Nilai Bobot Analisis Alternatif Strategi Pemasaran Keseluruhan

\begin{tabular}{lccc}
\hline \multicolumn{1}{c}{ Alternatif Strategi } & Bobot & Prioritas & Rasio Inkonsistensi \\
\hline Strategi Produk & 0.269 & 2 & \\
Strategi Harga & 0.209 & 3 & 0.00 atau 0\% \\
Strategi Distribusi & 0.162 & 4 & \\
Strategi Promosi & 0.360 & 1 & \\
\hline
\end{tabular}

Sumber: Data Primer Diolah (2016)

Table 4 diatas merupakan hasil keseluruhan analisis alternatif strategi pemasaran teh hitam merk alam dempo pada CV. Karya Sejahtera di Kota Pagar Alam. Strategi promosi yang menjadi prioritas yang pertama dengan bobot 0,360 dalam pemilihan strategi pemasaran teh hitam alam dempo. Menurut Grede (2006) dalam Fatma (2014), promosi merupakan salah satu elemen penting pada bauran pemasaran yang memiliki peran penting dalam rangka mencapai visi perusahaan yaitu mengkomunikasikan suatu produk sehingga keberadaannya terus diingat konsumen guna pencapaian keuntungan yang lebih besar. CV. Karya Sejahtera perlu melakukan strategi promosi guna memperkenalkan dan mempertahankan konsumen terhadap produk teh hitam alam dempo. Kecenderungan konsumen yang tidak loyal, yakni memilih produk terbaik dengan kualitas yang diinginkan, sepanjang harganya sesuai dengan ukuran. Dengan demikian, diharapkan pelaksanaan promosi yang efektif dapat merangsang konsumen untuk membeli produk tersebut. Promosi ini bisa dilakukan melalui periklanan dan pemasaran langsung, seperti melalui TV, Radio, Media cetak. Hal ini didasarkan bahwa banyak pengusaha industri teh hitam lainnya seperti Koperasi Ruwajurai, Koperasi lembah Gunung Dempo yang akan memasarkan produk di pasaran.

Strategi produk menjadi prioritas yang kedua dengan bobot yaitu sebesar 0.269. Konsumen memuaskan kebutuhan dan keinginan mereka melalui sebuah produk. Wahyuningsih (2014) menyatakan perusahaan memilih strategi tersebut karena menganggap bahwa kualitas produk serta pelayanan adalah sesuatu yang perlu dijaga dan ditingkatkan, karena hal tersebut akan memberikan kepuasan bagi pelanggan. Hal ini menyebabkan perusahaan harus selalu meningkatkan kualitas produk serta pelayanan. Dikarenakan produk teh hitam alam dempo bahan bakunya berasal langsung dari PTPN, maka strategi produk yang dilakukan seperti membuat bentuk kemasan yang menarik, sehingga akan menarik daya beli para konsumen.

Strategi Harga dijadikan prioritas ketiga dengan bobot sebesar 0,209. Harga memberikan pengaruh besar terhadap persepsi konsumen atas kualitas. Kesalahan menetapkan harga jual akan berdampak pada sikap konsumen yang kurang baik terhadap produk, layanan dan nama perusahaan. Penetapan harga merupakan salah satu bagian yang sangat penting dalam pemasaran teh hitam alam dempo. Karena harga merupakan penentu keberhasilan suatu perusahaan karena hargalah yang menentukan keuntungan yang diperoleh dari hasil penjualan. Dengan penetapan harga yang sesuai juga akan 
membantu memperluas jaringan pemasaran produk. Konsumen cenderung membeli pada harga yang relatif murah dan membandingkannya dengan harga kompetitor sebagai referensi perbandingan. Harga jual merupakan sejumlah biaya yang dikeluarkan perusahaan untuk memproduksi suatu barang atau jasa ditambah dengan persentase laba yang diinginkan perusahaan, karena itu harus mencapai laba yang diinginkan oleh perusahaan salah satu cara yang harus dilakukan untuk menarik minat konsumen adalah dengan cara menentukan harga yang tepat untuk produk yang terjual. Untuk harga produk teh hitam ini masih terjangkau di bandingkan produk pesaing teh hitam merk lainnya.

Strategi distribusi dijadikan prioritas terakhir dengan bobot nilai sebesar 0,162 . Keputusan mengenai saluran distribusi dalam pemasaran adalah merupakan salah satu keputusan yang paling kritis yang dihadapi manajemen. Saluran yang dipilih akan mempengaruhi seluruh keputusan pemasaran yang lainnya. Dalam rangka untuk menyalurkan barang dan jasa dari produsen kepada konsumen maka perusahaan harus benar-benar memilih atau menyeleksi saluran distribusi yang akan digunakan, sebab kesalahan dalam pemilihan saluran distribusi ini dapat menghambat bahkan dapat memacetkan usaha menyalurkan barang atau jasa tersebut. Pendistribusian yang baik adalah mendistribusikan produk ke toko-toko atau wilayah yang mudah dijumpah dan ramai oleh penduduk sehingga mudah untuk dijangkau oleh konsumen. Dalam memperluas daerah pendistribusiannya produk teh hitam alam dempo tentu harus melihat situasi yang mendukung dari wilayah tersebut, seperti melihat daya beli masyarakat, tingkat sosial masyarakat di wilayah tersebut dan yang lainnya.

\section{SIMPULAN DAN SARAN}

\section{Simpulan}

Dari proses pengolahan data dan analisis yang telah dilakukan, maka dapat diambil kesimpulan sebagi berikut:

1. Kriteria yang menjadi prioritas utama pemilihan strategi pemasaran teh hitam alam dempo pada CV. Karya Sejahtera adalah persaingan.

2. Untuk alternatif prioritas utama strategi pemasaran teh hitam alam dempo $\mathrm{CV}$. Karya Sejahtera yang terpilih dengan menggunakan metode AHP adalah strategi promosi.

\section{Saran}

Sebaiknya strategi pemasaran teh hitam pada CV. Karya Sejahtera ini menerapkan strategi promosi dengan memperhatikan persaingan. Strategi promosi teh hitam alam dempo dapat berupa memberikan promosi secara lebih luas lagi, seperti melaui TV lokal, media cetak sehingga menarik daya beli konsumen. 


\section{DAFTAR PUSTAKA}

Andri H, Andri dan Rina. 2015. Analisis Strategi Pemasaran Usaha Mie Basah (Studi Kasus Di PD. LUGINA -Garut). Jurnal Kalibrasi Sekolah Tinggi Teknologi Garut. 13 (1): 1-13.

Nimpatupulu, Anona. 1992. Pengendalian Hama, Penyakit dan Gulma di Perkebunan Teh: Pengendalian Hama. Penelitian Perkebunan Gambung. Bandung.

Fatma, Aulia Fitria. 2014. Analisis Strategi Promosi Menggunakan Analytical Hierarchy Process (AHP) (Studi Kasus di PT Sinar Sosro Kantor penjualan Wilayah (KPW) Waru, Sidoarjo-Jawa Timur). Jurnal Lulusan TIP FTP UB Agustus $2014: 1-8$.

Kotler, Philip, dan Amstrong, Gary. 2008. Prinsip-prinsip Pemasaran. Jakarta: Erlangga

Nuryasri, Salviani. 2014. Kajian Pengembangan Usaha Budidaya Ikan Air

Tawar dalam Mina Padi Di Desa A. Widodo Kecamatan Tugumulyo Kabupaten Musi Rawas. Skripsi Fakultas Petanian Universitas Bengkulu.

Marimin. 2004. Teknik dan Aplikasi Pengambillan Keputusan Kiteria Majemuk. PT Gramedia Widiasarana Indonesia. Jakarta.

Sukiyono, Ketut. 2013. Draft Buku Ajar Penelitian Survai dan Teknik Sampling. Fakultas Pertanian Universitas Bengkulu. Bengkulu.

Wahyuningsih, Ninik. 2014. Analisis Strategi Bauran Pemasaran Minuman Kopi Menggunakan Metode Analytical Hierarchy Process (AHP) dan Technique for Order Preference by Similarity to Ideal Solution (TOPSIS) (Studi Kasus pada Coffee Story Malang). Jurnal Teknologi Industri Pertanian, Fakultas Teknologi Pertanian Universitas Brawijaya. Malang.

Wijaya, Galuh Dian Paramita. 2014. Strategi Pemasaran Berdasarkan Anlisis Bauran Pemasaran Terhadap Keputusan Pembelian Konsumen Produk Buah Apel Malang di Giant Mall Olympic Garden (MOG). Jurnal Lulusan TIP FTP UB September 2014: 1-9.

Valentina, Oxy. 2009. Analisis Nilai Tambah Ubi Kayu Sebagai Bahan Baku Kripik Singkong di Kabupaten Karang Anyar. Skipsi Fakultas Pertanian Universitas Sebelas Maret. Surakarta.

Wahyu, Dendi. 2011. Analisis Distribusi Nilai Tambah Pengolahan Kopi pada Industri Kopi Bubuk Sehati. Fakultas Pertanian Universitas Andalas. Sumatra Barat.

Zumroh, Isti. 2014. Penggunaan Analisis SWOT dan AHP Untuk Menentukan

Strategi Pemasaran Perusahaan (Studi Kasus: WL. ALUMUNIUM). Fakultas Sains dan Teknologi. Yogyakarta. 